\title{
The Effect of Chemical Composition and Production Technology on the Mechanical Properties of EN AW-8006 Alloy
}

\author{
Judit PÁZMÁN, ${ }^{1}$ Jánosné FEHÉR, ${ }^{2}$ Viktor GONDA, ${ }^{3}$ Balázs VERŐ ${ }^{4}$ \\ ${ }^{1}$ University of Dunaujvaros, Institute of Technology, Department of Materials Science, Dunaújváros, \\ Hungary, pazman@uniduna.hu \\ ${ }^{2}$ University of Dunaujvaros, Institute of Technology, Department of Materials Science, Dunaújváros, \\ Hungary, feherjanosne@uniduna.hu \\ ${ }^{3}$ Óbuda University, Bánki Faculty of Mechanical and Safety Engineering, Institute of Materials and \\ Manufacturing, Budapest, Hungary, gonda.viktor@bgk.uni-obuda.hu \\ ${ }^{4}$ University of Dunaujvaros, Institute of Technology, Department of Materials Science, Dunaújváros, \\ Hungary,verob@uniduna.hu
}

\begin{abstract}
Aluminum alloys EN AW-8006 with three different Fe:Mn ratios were studied. In the experiments, the temperature of the intermediate soft-annealing between the cold rolling processes and the final soft-annealing at the end of the production technology were varied. The processed samples were subjected to tensile testing and hardness measurements. The effect of chemical composition, based on the test results, showed that for samples without intermediate softening, only the increase of iron content has a significant effect on the yield stress, and the change of iron content refined the final grain structure compared to the reference material.
\end{abstract}

Keywords: $E N A W$-8006, chemical composition, intermediate annealing, tensile test.

\section{Introduction}

The $8 x x x$ category of aluminum alloys includes special alloys of aluminum. The most important types are EN AW-8006 (AlFeMn), Al8011 (AlFeSi), and Al8018 (Al-FeSiCu) [1]. By evaluating the conditions of the Hume-Rothery rule for unlimited solubility, it is clear that these alloying elements are not - or only to a limited extent - soluble in solid aluminum. The limited solubility, in turn, induces the formation of compound phases, even as a first step in crystallization. Iron and manganese as transition elements promote the formation of intermetallic phases to which diamond latticed silicon contributes too. Thus, in the dendritic spaces in the $8 \mathrm{xxx}$ alloys, there are intermetallic phases, the amount and shape of which also strongly determine the manufacturing technology and end use of the selected product itself. The present work deals with the EN AW-8006 alloy in such a way that, on the one hand, chemical compositions within the standard are changed and, on the other hand, the production technology is optimised. The difference between the chemical composition modifications is the ratio of iron and manganese in the two main alloying elements, which determine the type of Al-Fe-Mn compounds in the interdental spaces and thus their morphology. Considering the two-component phases at the aluminum-rich corner of the $\mathrm{Al}$-Fe-Mn ternary system; $\mathrm{FeAl}_{3}, \mathrm{MnAl}_{6}$ and $\mathrm{AlMn}_{4}$ phases are formed during crystallization. However, manganese can replace the site in $\mathrm{MnAl}_{6}$ with iron and form a tricomponent compound with $\mathrm{FeMnAl}_{12}$ contents of $13 \%$ Fe and 14\% Mn [2-3]. This is the so-called (Fe, Mn) Al6 phase. The shape, size and number of phases during crystallization are determined by the rate of cooling; in terms of chemical composition, it is also influenced by the presence of additional and micro alloying elements, the total amount of $\mathrm{Fe}, \mathrm{Mn}$ and $\mathrm{Si}$, and the grain refining process [4]. Among the alloying elements, the incorporation of copper into the lattice of the intermetallic phase is able to stabilize the 
lamellar structure characteristic of Al-Fe phases, as well as high heat treatment at high temperatures, e.g. during homogenization, it prevents the phases from redissolving and spheroidizing, thus complicating the processing, i.e. hot and cold rolling (Figure 1. ) [5].

Large lamellar phases cause the formation of socalled "pencil phases" during the plastic forming process, the grouping of which easily lead to rupture of the final product, such as the rupture of a $200 \mu \mathrm{m}$ thick foil (Figures 2-3. ) [6].

Remaining within the standard range of composition, chemical composition was slightly changed to create the most favourable phase structure as possible. The aim is to identify the phases that reduce the volume fraction of the pencil phases in the formed alloy.

Figure 4. shows the phase stages of the Fe:Mn ratio, and the chemical composition variants were developed accordingly. On the selected chemical alloys, homogenization, hot rolling, cold rolling, and between the cold rolls were achieved with intermediate soft-annealing in one half of

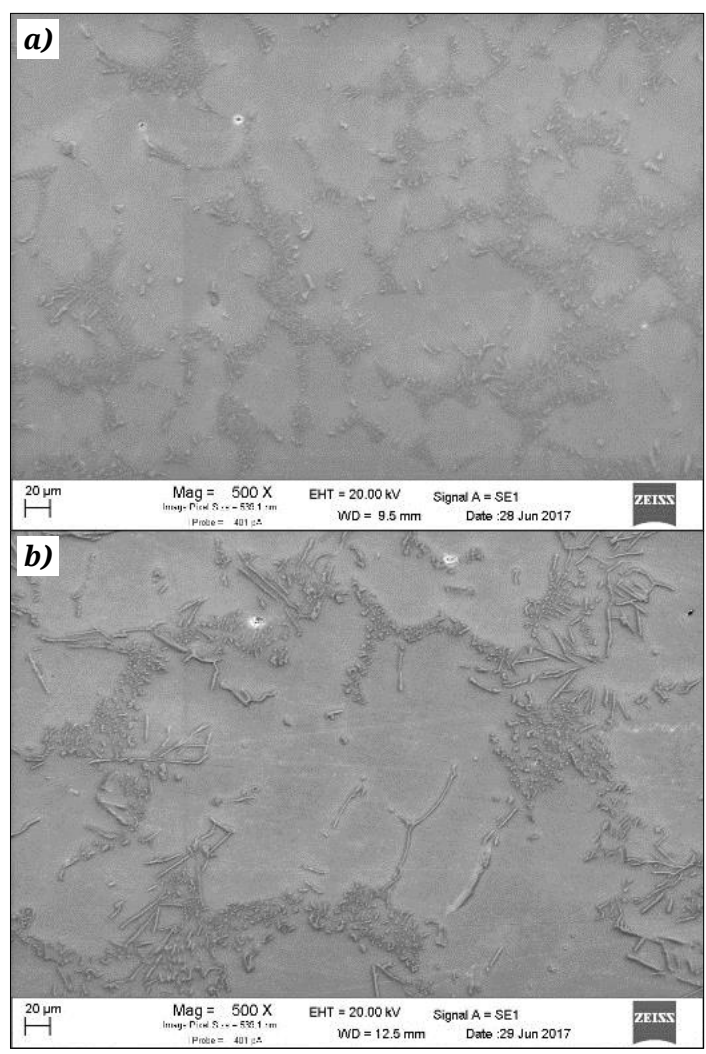

Figure 1. AThe phase structure of EN AW-8006 alloy a) EN AW-8006 alloy without $\mathrm{Cu}$; b) EN AW-8006 alloy with $\mathrm{Cu}$.

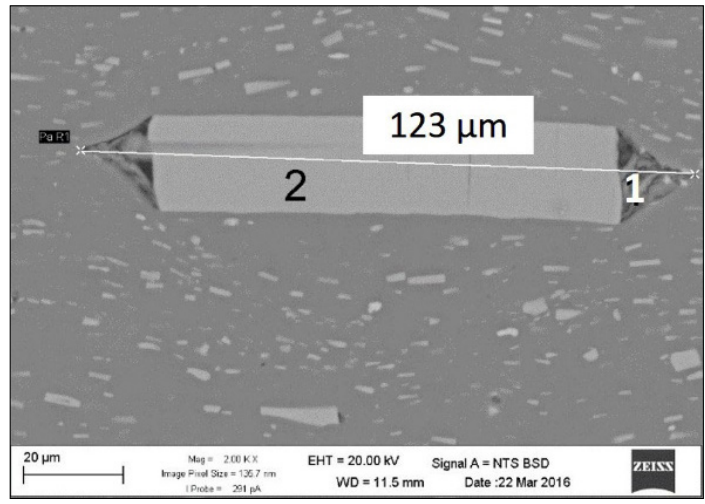

Figure 2. Large „pencil” phase in EN AW-8006 alloy 1 - hole with the resin; $2-73,8 w \% A l, 19,5 w \%$ Fe, 6,7w\%Mn.

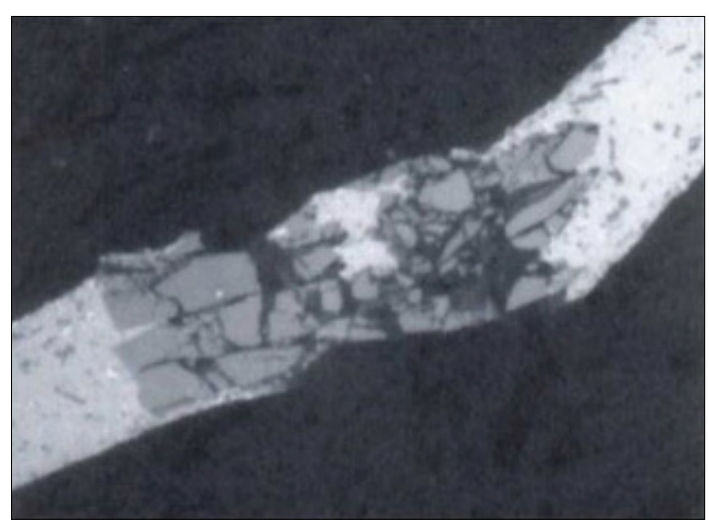

Figure 3. The rupture of foil due to the agglomeration of „pencil” phase.

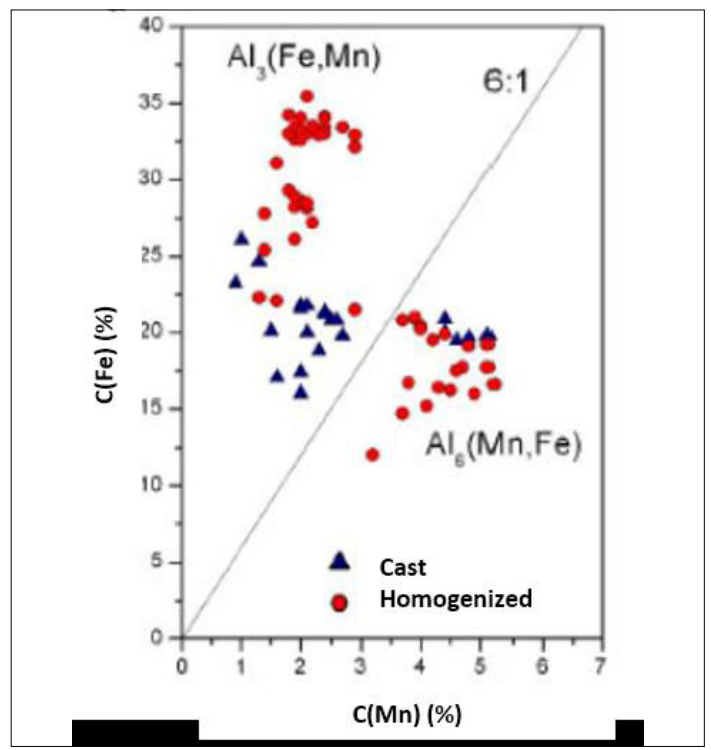

Figure 4. The compound forming role of Fe:Mn ratio in EN AW-8006 alloy. 
the samples and no intermediate soft-annealing in the other half. The last step in the technological sequence of operations was soft-annealing at the final thickness.

\section{Experimental}

To select the chemical composition of the alloy, the Standard starting chemical composition of EN AW-8006 alloy was used, according to which $1.2-2 \%$ Fe, max. $0.4 \% \mathrm{Si}$, max. $0.3 \% \mathrm{Cu}, 0.3-1 \% \mathrm{Mn}$, max. $0.1 \% \mathrm{Mg}$, max. $0.1 \% \mathrm{Zn}$, others $\mathrm{Al}$.

Based on findings in the literature and our preliminary homogenization experiments, the following basic concept was developed to determine the chemical composition variants:

1. The copper-free EN AW-8006 alloy is considered as the reference material, hereinafter referred to as EN AW-8006_R as the reference material.

2. The amount of contaminants is minimized, so that a purer alloy is produced in order to reduce the amount of secondary phases formed from the contaminants.

3. In the case of the composition variants, the $\mathrm{Fe} /$ Mn ratio is varied, even without modifying the amount of $\mathrm{Mn}$, because increasing this alloying element induces foundry problems, e.g. slurry formation. So the amount of iron was increased or decreased Table 1. shows the alloys variants compositions.

Thus, the ratio of the two elements in the first case, where the notation is $\mathrm{R}$, is the Fe/Mn ratio: 3.15. In the second case, where the notation is csFe - reduced iron content: $\mathrm{Fe} / \mathrm{Mn}$ ratio $=3$. In the third case, where the Fe $/ \mathrm{Mn}$ ratio $=3.875$, denoted by $n F e$ - increased iron content. Table 1 shows the amounts of alloying elements.

In addition to the modification of the chemical composition, the production process of the alloys was also changed in such a way that, after the hot rolling, cold rolling was carried out with and without intermediate soft-annealing. In this way, the effect of intermediate soft-annealing was

Table 1. Chemical composition of EN AW-8006 alloy variants

\begin{tabular}{|l|c|c|}
\hline \multicolumn{1}{|c|}{ Sample name } & Fe (\%) & Mn (\%) \\
\hline \multirow{2}{*}{ EN AW-8006_R } & 1.05 & 0.3 \\
& 1.15 & 0.4 \\
\hline \multirow{2}{*}{ EN AW-8006_csFe } & 1.15 & 0.3 \\
& 1.25 & 0.4 \\
\hline \multirow{2}{*}{ EN AW-8006_nFe } & 1.3 & 0.3 \\
& 1.5 & 0.4 \\
\hline
\end{tabular}

studied on the particle structure and mechanical properties of the final product. The intermediate soft-annealing was accomplished with different temperature and time parameters on the samples of the selected composition, so that the best set of soft-annealing parameters for the given composition could be given. Also, the optimum for this technological step by changing the temperature and time parameters of the final thickness softening was investigated.

From the alloys of different chemical compositions, $50 \mathrm{~mm}$ thick small blocks were cast, homogenized at $605^{\circ} \mathrm{C}$, then hot-rolled at $500^{\circ} \mathrm{C}$ to a thickness of $5.2 \mathrm{~mm}$, and then some of the samples were cold-rolled without intermediate soft-annealing until $0.5 \mathrm{~mm}$ final thickness. The other half of the samples were cold-rolled to a thickness of $1 \mathrm{~mm}$ after hot forming, at which point they received the intermediate soft-annealing, and then the cold forming was completed at $0.5 \mathrm{~mm}$. The intermediate soft-annealing temperatures at $1 \mathrm{~mm}$ were $320^{\circ} \mathrm{C}, 340^{\circ} \mathrm{C}, 360^{\circ} \mathrm{C}$ and $380^{\circ} \mathrm{C}$. Final soft-annealing temperature at $0.5 \mathrm{~mm}$ was $220^{\circ} \mathrm{C}$, $260^{\circ} \mathrm{C}, 300^{\circ} \mathrm{C}, 340^{\circ} \mathrm{C}$ and $380^{\circ} \mathrm{C}$. The soft-annealing time was $2 \mathrm{~h}$ at each temperature. The samples thus prepared were subjected to tensile testing, as well as microhardness measurements and microstructural analysis.

Figure 5. shows the effect of intermediate softening on the hardness values of the alloy compositions, based on which, it is clear that the alloy already shows partial softening at $320^{\circ} \mathrm{C}$ and the hardness changes only slightly with increasing temperature. There are no substantive differences between the chemical composition variations. The complete softening occurs at $340^{\circ} \mathrm{C}$.

The intermediate softened piece was formed to final thickness and then final soft-annealed.

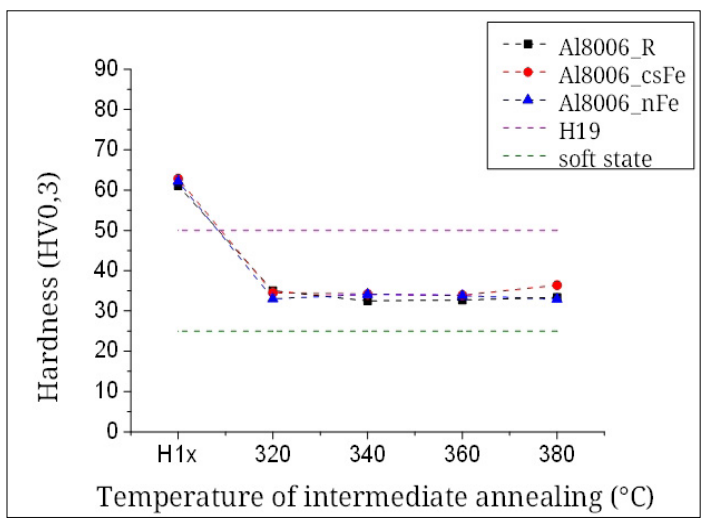

Figure 5. The effect of intermediate annealing on the hardess of deformed samples. 
It can be clearly seen from the diagrams of Figure Figure 6. that the alloy partially softens at $260^{\circ} \mathrm{C}$, regardless of the chemical composition variants, and the hardness changes only slightly with increasing temperature. Complete softening occurs at $300^{\circ} \mathrm{C}$.

For samples without intermediate softening, the diagrams in Figure 7. show the hardness values after final softening.

According to the diagrams of Figure Figure 7 , if the intermediate softening is removed from the technological step sequence, the alloy will soften at $300^{\circ} \mathrm{C}$ as in the case of the intermediate softened samples, but the degree of partial softening - based on the hardness measurement data - is significantly lower than for intermediate softened samples. No substantial difference can be detected between the chemical composition variants.

Reviewing the results of the tensile test, the samples without intermediate softening produce higher values at the yield strength values, which

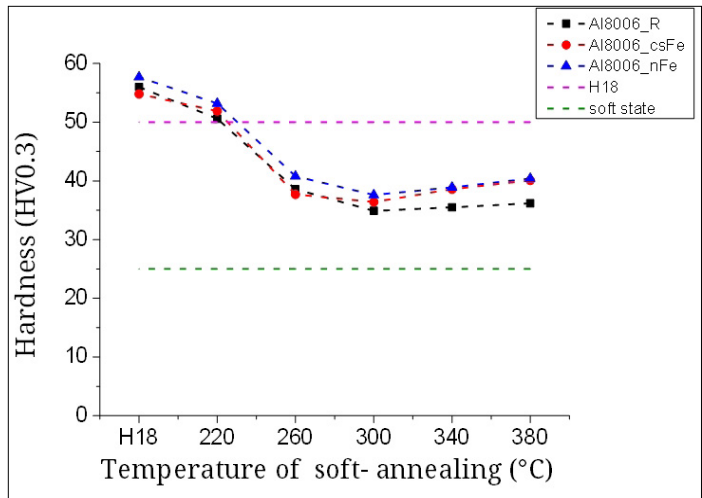

Figure 6. The effect of final soft-annealing on the hardness of intermediate annealed samples.

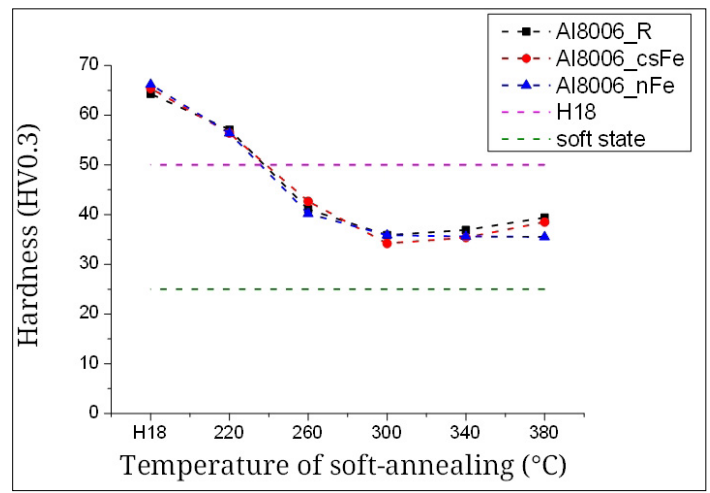

Figure 7. The effect of final soft-annealing on the hardness of deformed samples. results from the formed state. Considering the chemical composition variants, the alloy with increased iron content shows a higher value, while the other two compositions are nearly identical. These differences in tensile strength and elongation at break are not observed, nor is the effect of softening or differences in chemical composition. (Figure 8.) The dashed lines in the diagram (Figure 8.) show the values of the standard required
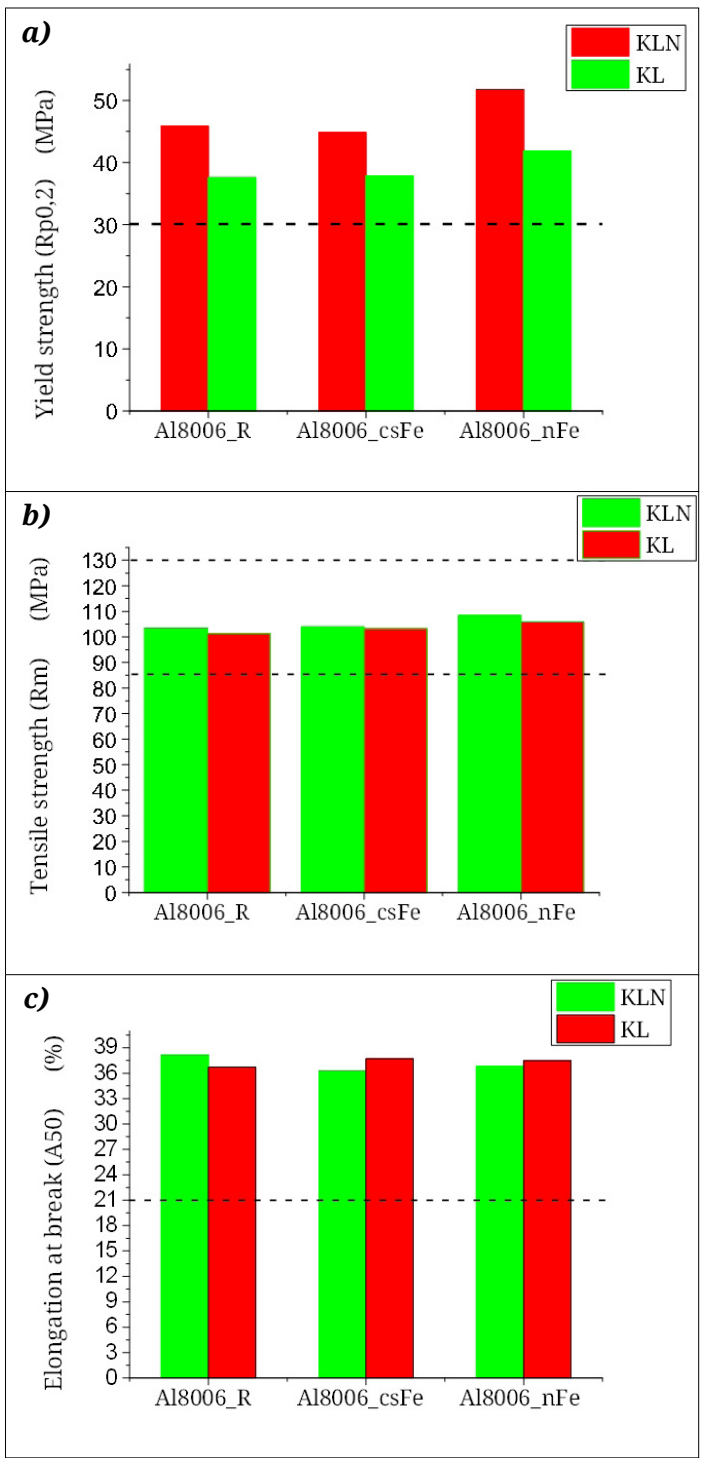

Figure 8. AThe effect of the chemical composition and intermediate soft-annealing on the mechanical proerties

a) Yield strength;

b) Tensile strength;

c) Elongation at break. 
mechanical properties for the soft state of a given alloy, on the basis of which all three chemical composition variants reach or even exceed the desired values

In addition to the mechanical tests, a microstructural analysis was also performed. Metallographic images show the microstructure of the samples without intermediate soft-annealing (Figure 9.) and of the intermediate soft-annealed (Figure 10.), already rolled to final thickness as a function of the chemical composition. Analysing the effect of intermediate softening for each composition, the grain structure - according to ASTM E112-96 standards - is significantly larger in the
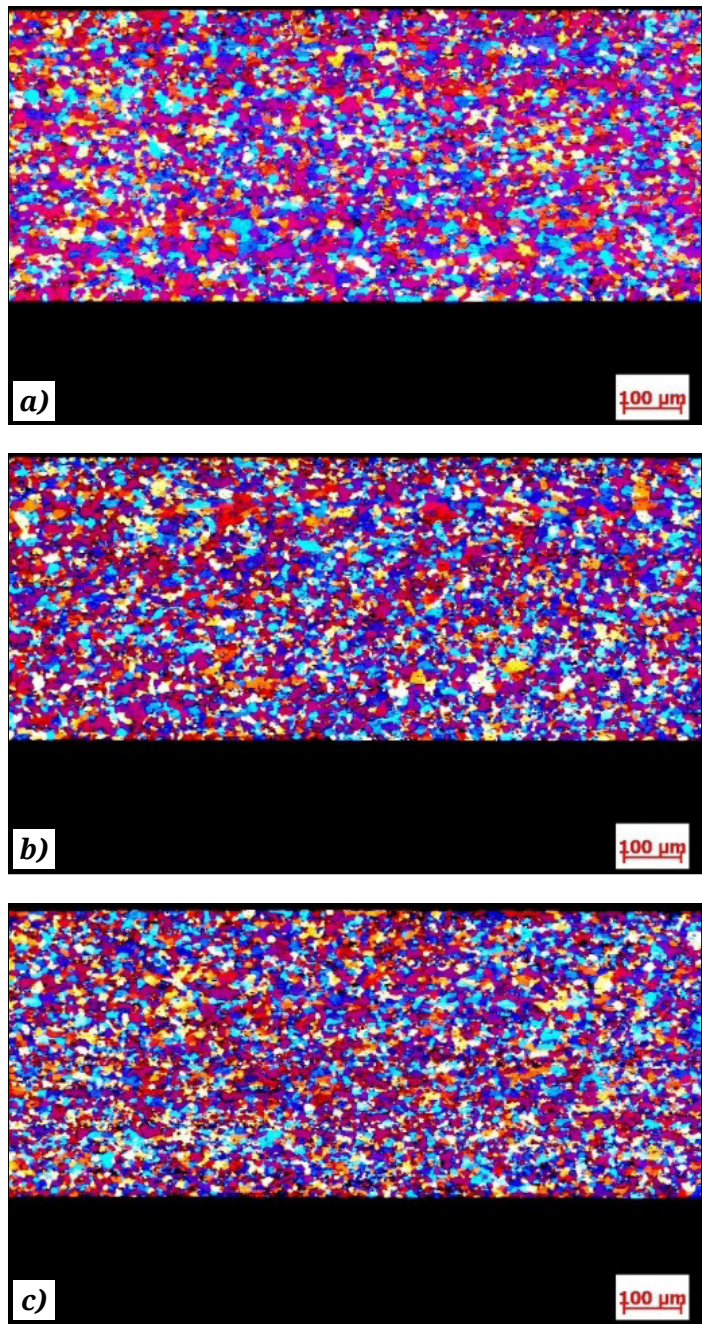

Figure 9 . Microstructure without the applying of soft-annealing

a) reference material;

b) alloy with decreased iron concentration;

c) alloy with increased iron concentration. case of sample $R(G=6.5-7)$ but this significant difference is no longer observed in the case of alloys with reduced $(G=7.5-8)$ and increased $(G=$ 8-8.5) iron content (Figure 9.). It should be noted that there is an increase in particle size here as well, but not to the same extent as for the reference material. Regarding the effect of the chemical composition, the difference is not noticeable in the samples without intermediate softening. A larger difference and a much finer microstructure can be observed in the intermediate softened samples, where changing the iron content, i.e. changing, increasing and decreasing the $\mathrm{Fe} / \mathrm{Mn}$ ratio, causes a significant grain refinement,
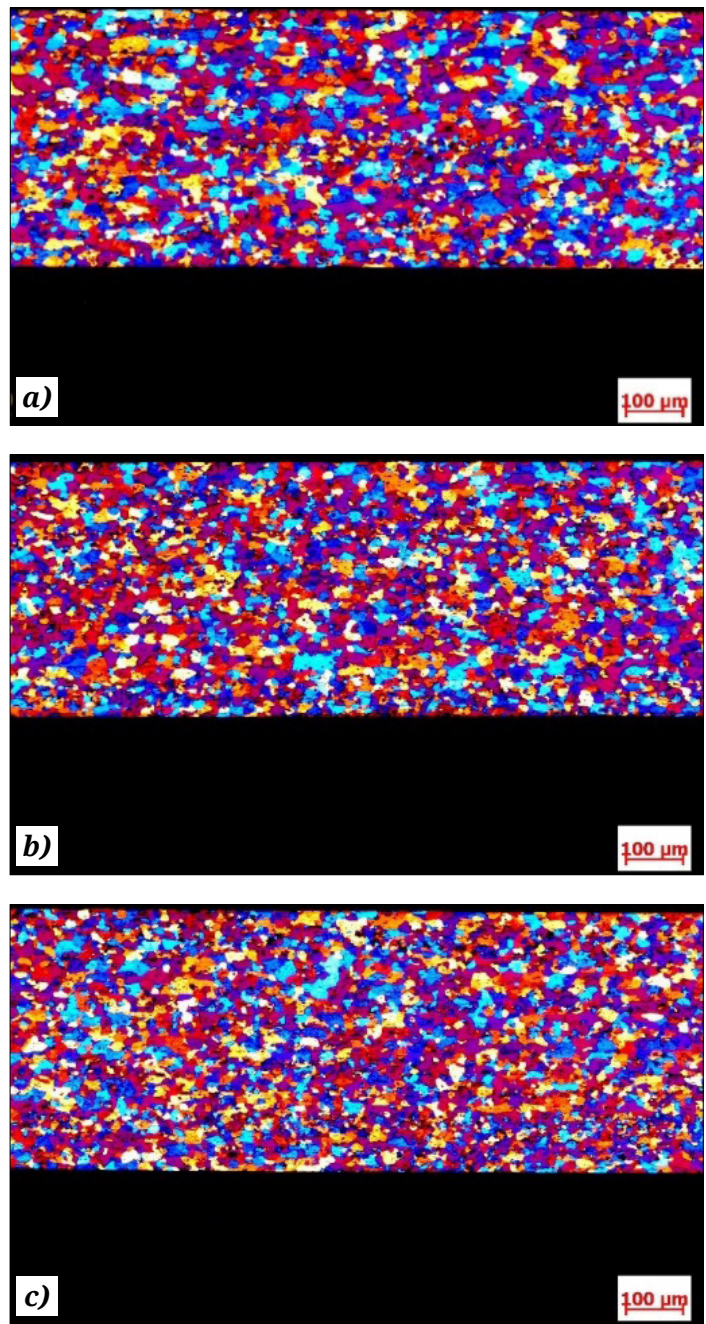

10. ábra. Microstructure with applying of soft-annealing

a) reference material;

b) alloy with decreased iron concentration;

c) alloy with increased iron concentration. 
it means $G=6-6.5$ for sample of $R, G=6.5-7$ for sample of csFe, and $G=7-7.5$ for sample of $n F e$, which can be attributed to the changed primary phase structure (Figure 10).

\section{Conclusions}

In this study, the EN AW-8006 alloy was tested by preparing three chemical composition variants and performing homogenization, hot rolling, cold rolling and intermediate softening in one half of the samples, and final softening in each case. Based on the results of tensile tests, hardness measurements and microstructure analysis performed on samples of different chemical composition and manufacturing technology, the following conclusions can be made:

1. Differences in chemical composition generate significant differences in yield strength values, with increased iron content yield yields above $50 \mathrm{MPa}$ can be achieved without intermediate softening. No significant difference can be detected in either the tensile strength or the elongation at break by changing the chemical composition or by using intermediate softening.

2. The increased or decreased iron content, ie the change of the Fe:Mn ratio, has an effect on the particle structure of the intermediate softened and then softened samples, a finer structure with a smaller particle size can be created.

\section{Acknowledgement}

The authors would like to thank GINOP-2.2.115-2016-00018 "Development of the technology of new, marketable rolled aluminum products, based on the latest results of technical materials science, the market-leading Hungarian industrial company, ARCONIC-Köfém Kft. + In cooperation with the universities', furthermore and EFOP-3.6.1-162016-00003 project "Long-term strengthening of R \& D \& I processes at the University of Dunaújváros” and EFOP-3.6.2-16-2017-00016 Dynamics and control of autonomous vehicles in synergy with the requirements of automated transport systems for the feasibility of experiments. The project was supported by the European Union and co-financed by the European Social Fund.

\section{References}

[1] Moldovan P., Popescu G., Miculescu F.: Microscopic study regarding the microstructure evolution of the 8006 alloy in the plastic deformation process. Journal of Materials Processing Technology, 153-154. (2004) 408-415. https://doi.org/10.1016/j.jmatprotec.2004.04.345

[2] Englera O., Laptyeva G., Wang N.: Impact of homogenization on microchemistry and recrystallization of the $\mathrm{Al}-\mathrm{Fe}-\mathrm{Mn}$ alloy $\mathrm{AA} 8006$. Materials Characterization, 79. (2013) 60-75. https://doi.org/10.1016/j.matchar.2013.02.012

[3] Warmuzek M., Gazda A., Sieniawski J.: Processes of the formation of the $\mathrm{Fe}(\mathrm{Mn})$-bearing intermetallic phases in the Al-Fe-(Mn)-Si alloys. Advances in Materials Science, 4/2(4). (2003). 81-91. bwmeta1. element.baztech-article-BPG5-0015-0041.

[4] Lentz M., Laptyeva G., Enger, O.: Characterization of second-phase particles in two aluminium foil alloys. Journal of Alloys and Compounds, 660. (2016) 276-288. https://doi.org/10.1016/j.jallcom.2015.11.111

[5] Mundson D.: A clarification of the phases occurring in aluminium-rich aluminium-iron-silicon alloys, with particular reference the ternary phase $\alpha$-AlFeSi. Journal of the Institute of Metals, 95. (1967) 217-219.

[6] Keles O., Dundar M.: Aluminum foil: Its typical quality problems and their causes. Journal of Materials Processing Technology, 186. (2007) 125-137. https://doi.org/10.1016/j.jmatprotec.2006.12.027 